\title{
An in Situ Atlas of Mitochondrial DNA in Mammalian Tissues Reveals High Content in Stem and Proliferative Compartments
} Check for updates

\author{
Jiayu Chen, ${ }^{*}$ Qizhi Zheng, ${ }^{*}$ Lauren B. Peiffer, ${ }^{* \dagger}$ Jessica L. Hicks, ${ }^{*}$ Michael C. Haffner, ${ }^{\star \star}$ Avi Z. Rosenberg, ${ }^{*}$ Moshe Levi, \\ Xiaoxin X. Wang, ${ }^{\S}$ Busra Ozbek, ${ }^{*}$ Javier Baena-Del Valle, ${ }^{*}$ Srinivasan Yegnasubramanian, ${ }^{\star \top}$ and Angelo M. De Marzo ${ }^{* \neq \Phi}$
}

\begin{abstract}
From the Departments of Pathology, * Molecular and Comparative Pathobiology, ${ }^{\dagger}$ and Urology and Oncology, ${ }^{\boldsymbol{\top}}$ and the Sidney Kimmel Comprehensive Cancer Center, ${ }^{\ddagger}$ Johns Hopkins University School of Medicine, Baltimore, Maryland; and the Department of Biochemistry and Molecular and Cellular Biology, ${ }^{\S}$ Georgetown University, Washington, DC
\end{abstract}

\author{
Accepted for publication \\ March 19, 2020. \\ Address correspondence to \\ Angelo M. De Marzo, M.D. \\ Ph.D., Department of Pathol- \\ ogy, Johns Hopkins University \\ School of Medicine, CRB-2/ \\ Room 144, 1550 Orleans St. \\ Baltimore, MD 21231. E-mail: \\ ademarz@jhmi.edu.
}

\begin{abstract}
Mitochondria regulate ATP production, metabolism, and cell death. Alterations in mitochondrial DNA (mtDNA) sequence and copy number are implicated in aging and organ dysfunction in diverse inherited and sporadic diseases. Because most measurements of mtDNA use homogenates of complex tissues, little is known about cell-type-specific mtDNA copy number heterogeneity in normal physiology, aging, and disease. Thus, the precise cell types whose loss of mitochondrial activity and altered mtDNA copy number that result in organ dysfunction in aging and disease have often not been clarified. Here, an in situ hybridization approach to generate a single-cell-resolution atlas of mtDNA content in mammalian tissues was validated. In hierarchically organized self-renewing tissues, higher levels of mtDNA were observed in stem/proliferative compartments compared with differentiated compartments. Striking zonal patterns of mtDNA levels in the liver reflected the known oxygen tension gradient. In the kidney, proximal and distal tubules had markedly higher mtDNA levels compared with cells within glomeruli and collecting duct epithelial cells. In mice, decreased mtDNA levels were visualized in renal tubules as a function of aging, which was prevented by calorie restriction. This study provides a novel approach for quantifying species- and cell-type-specific mtDNA copy number and dynamics in any normal or diseased tissue that can be used for monitoring the effects of interventions in animal and human studies. (Am J Pathol 2020, 190: 1565-1579; https://doi.org/10.1016/j.ajpath.2020.03.018)
\end{abstract}

Mitochondria are critical for many cellular functions including ATP production, metabolism, macromolecular synthesis, calcium homeostasis, cell signaling, and programed cell death. ${ }^{1}$ Mitochondria have their own genome [mitochondrial DNA (mtDNA)], encoding 13 proteins involved in oxidative phosphorylation, 22 tRNAs, and 2 rRNAs required for mitochondrial ribosome function. Over the last few decades, a large number of genetic diseases of mitochondrial function have been characterized that are caused by maternally inherited mutations in the mitochondrial genome, or by nuclear encoded genes whose products function in mitochondria. ${ }^{1,2}$ These mutations often result in disorders of the nervous system (eg, epilepsy, deafness, neuropathy, ataxia), skeletal muscle (eg, weakness,

\footnotetext{
Supported by NIH/National Cancer Institute (NCI) Specialized Programs of Research Excellence (SPORE) in Prostate Cancer grant P50CA58236 (A.M.D.M.), NIH/NCI grant U01 CA196390 (A.M.D.M., S.Y.), U.S Department of Defense Prostate Cancer Research Program (PCRP) grant W81XWH-18-2-0015 (A.M.D.M.); National Institute of Diabetes and Digestive and kidney diseases (NIDDK) grant R01 DK116567 (M.L.); and National Institute of Aging (NIA) grant R01 AG049493 (M.L.). The Johns Hopkins Sidney Kimmel Comprehensive Cancer Center Oncology Tissue Services Laboratory is supported by NIH/NCI grant P30 CA006973. Fluorescent confocal microscopy reported in this publication was supported by the Office of the Director of the National Institutes of Health under award number S10OD016374 (Johns Hopkins University School of Medicine Microscope Facility).

Disclosures: None declared.

Current address of M.C.H., Human Biology Division, Fred Hutchinson Cancer Research Center, Seattle, WA; of J.B.-D.V., Department of Pathology, Fundación Santa Fe de Bogotá, Bogotá, Colombia.
} 
ophthalmoplegia), and cardiac muscle (eg, cardiomyopathy). Interestingly, a number of inherited diseases caused by mtDNA mutations, or mutations in nuclear genes whose products function in mitochondria, demonstrate organspecific and cell-type-specific phenotypes. ${ }^{3}$

Mitochondrial dysfunction can also be acquired in the absence of inherited mutations and has been linked to declines of function with aging in several organ systems and to age-related cardiovascular and neurodegenerative diseases, as well as cancer. ${ }^{4-7}$ Whether these age-related declines in mitochondrial function directly result from the known accumulation of somatic mtDNA mutations, or subgenomic deletions with age, is still unclear. ${ }^{6,8}$

Mitochondrial function can be regulated through mitochondrial biogenesis, which is controlled in a cell-typeand tissue-specific manner, and is determined in part by regulating mtDNA copy number. ${ }^{9}$ As such, there has been interest in measuring mtDNA copy number (independent of mtDNA mutations) in aging and diseased tissues. ${ }^{10-16}$ In human studies, although there is general agreement that mtDNA copy number declines with age in peripheral blood mononuclear cells, ${ }^{17-20}$ no consensus has been reached regarding mtDNA copy number changes with aging in non-blood-related tissue types. ${ }^{15}$ This is the case even in skeletal muscle, in which both overall cellular/organ function and mitochondrial function are well-known to decline with age. The discrepancies in the results from these studies do not appear to be explained simply by methodological differences. ${ }^{15}$ Because widely employed strategies for measuring mtDNA levels are performed using solutionbased methods after cellular disruption/homogenization of bulk tissues, the measurements necessarily reflect a composite of heterogeneous cell types. Some of the discrepancies result from the multiple cell types in a tissue, whose proportions may vary with inflammation, regeneration, fibrosis, and other age-related processes. ${ }^{8}$ One method to circumvent the problem of heterogeneous cell types is to isolate specific cell populations (eg, in the liver and central nervous system) by laser-capture microdissection followed by quantitative PCR (qPCR) or genomic sequencing. ${ }^{16,21}$ Yet, even using laser capture, it can be very difficult to evaluate specific cell types or single cells across tissue samples. Therefore, an in situ method for mtDNA measurements would be advantageous. Although prior studies have used in situ approaches to localize mtDNA in cells and tissues, these methods were used in limited applications, such as those regarding mtDNA replication and transcription, as well as to examine mtDNA levels in specific cell populations in a single tissue type or disease state. ${ }^{22-33} \mathrm{In}$ this study, the authors developed a novel quantitative in situ assay to interrogate mtDNA at the single-cell level in formalin-fixed, paraffin-embedded (FFPE) or frozen archival tissue. In contrast to bulk methods, this in situ approach can be implemented using standard bright-field microscopy facilitating rapid spatial determination of mtDNA content at single-cell resolution in complex tissues.

\section{Materials and Methods}

\section{Cell Culture and Treatment}

Prostate cancer cell lines CWR22Rv1 (CRL-2505), LNCaP (CRL-1740), DU145 (HTB-81), and PC3 (CRL-1435) were obtained from ATCC (Manassas, VA). All cell lines were cultured in RPMI 1640 with L-glutamine medium (Corning, Corning, NY) and 10\% heat-inactivated BenchMark fetal bovine serum (Gemini Bio-Products, West Sacramento, CA). Cells were maintained in $75 \mathrm{~cm}^{2}$ or $175 \mathrm{~cm}^{2}$ tissue culture flasks (Sarstedt, Nümbrecht, Germany) in a humidified incubator at $37^{\circ} \mathrm{C}$ with $5 \% \quad \mathrm{CO}_{2}$. When reaching approximately $85 \%$ confluency, cells were passaged using TrypLE Express Enzyme without phenol red (Thermo Fisher Scientific, Waltham, MA). All cell lines were authenticated using short tandem repeat profiling by the Genetic Resources Core Facility at The Johns Hopkins University School of Medicine.

To generate cells with different levels of mtDNA, CWR22Rv1 and PC3 cells were cultured in RPMI 1640 with L-glutamine medium (Corning) containing 2',3'-dideoxycytidine (ddC) (D5782, MilliporeSigma, Burlington, MA), $10 \%$ fetal bovine serum, $1 \mathrm{mmol} / \mathrm{L}$ sodium pyruvate (Thermo Fisher Scientific) and $50 \mu \mathrm{g} / \mathrm{mL}$ uridine (MilliporeSigma). ddC-containing medium was replaced twice a week. Cell lines with forced overexpression of MYC by lentiviral transduction were prepared as described previously. ${ }^{34}$

\section{Cell Block Preparation}

FFPE cell blocks were generated using the protocols described previously, with the following modifications. ${ }^{35}$ Cells were harvested by trypsinization as above, washed once with phosphate-buffered saline (PBS), and resuspended in approximately $150 \mu \mathrm{L}$ of $10 \%$ neutral buffered formalin (NBF). The resuspended cells were transferred to a $0.5-\mathrm{mL}$ microcentrifuge tube with solidified $2 \%$ agarose prefilled in the tapered portion of the bottom, and spun down in a swinging bucket centrifuge at $540 \times g$ for 5 minutes. The resulting supernatant was removed, and fresh $10 \%$ NBF was added without disturbing the pellet. The microcentrifuge tube was spun at $810 \times g$ for 5 minutes, and the resulting cell plug was fixed in formalin for 48 hours at room temperature by submerging the microcentrifuge tube into a $15-\mathrm{mL}$ conical tube containing $10 \% \mathrm{NBF}$. After fixation, the microcentrifuge tubes were transferred to a new $15-\mathrm{mL}$ conical tube with PBS and stored at $4{ }^{\circ} \mathrm{C}$ prior to processing and embedding in paraffin blocks.

\section{Human Prostate, Small Intestine, Liver, Kidney, and Tissues}

Prostate tissues were obtained from radical prostatectomies for prostate cancer. Human duodenum (small intestine) was obtained as frozen tissue samples of grossly normal 
duodenum from patients undergoing pancreatoduodenectomy for pancreatic cancer. Human liver and kidney tissues were obtained from samples of patients undergoing autopsy for metastatic prostate cancer. This study was approved by the Johns Hopkins institutional internal review board.

\section{Normal Mouse Tissues}

Experimentally unmanipulated wild-type normal FVB/N mice [derived from FVB-Tg (ARR2/Pbsn-MYC)7Key/Nci] were conventionally housed according to protocols approved by the Animal Care and Use Committee at Johns Hopkins University. Animals ( 2 to 3 months, $n=3$ for each sex) were euthanized, and necropsied as previously described, ${ }^{36}$ and tissues were fixed in 10\% NBF or Formical-2000 for bone tissues samples (StatLab, McKinney, TX) for 48 hours and processed into FFPE blocks as above.

\section{Mouse Aging and Calorie Restriction Study}

Male C57BL/6 mice (Charles River Laboratories, Wilmington, MA) were housed and maintained on a 12 hours lightdark cycle, at a constant temperature $\left(22 \pm 2^{\circ} \mathrm{C}\right)$ and relative humidity $(55 \pm 15 \%)$, and treated as described. ${ }^{37}$ Mice were randomly divided into the following groups: group 1-control young (6 months, $n=3$ ); group 2-control aging (24 months, $n=3$ ), and group 3-aging with calorie restriction (24 months, $n=3$ ). Tap water was available ad libitum, and rodent diets were available ad libitum for groups 1 and 2. For group 3, mice were calorie restricted ( $40 \%$ calorie reduction) from 14 weeks of age. Immediately following euthanasia, the kidneys were harvested and processed for FFPE.

\section{mtDNA CISH Assay}

Chromogenic in situ hybridization (CISH) of mtDNA on FFPE tissues and FFPE cell blocks was performed manually following the instructions from the manufacturer [Advanced Cell Diagnostic (ACD), Newark, CA] using RNAscope 2.5 HD Assay-BROWN Detection Kit (ACD) with the following modifications. ${ }^{38}$ Slides were baked at $60^{\circ} \mathrm{C}$ for 30 minutes, deparaffinized in xylene 3 times for a total of 20 minutes, and immersed twice in 100\% ethanol for 4 minutes. Slides were then incubated in pretreatment I solution (hydrogen peroxide) for 10 minutes at room temperature, and steamed in pretreatment II solution for 18 minutes. Slides were dipped in deionized water $\left(\mathrm{diH}_{2} \mathrm{O}\right)$ with $0.1 \%$ Tween 20 (P7949; MilliporeSigma) once, and incubated in Protease Plus solution at $40^{\circ} \mathrm{C}$ as pretreatment III. The protease digestion time depended on the sample types and species, from 10 minutes (human cell blocks) to 20 or 30 minutes for the human and mouse tissues. Slides were incubated in HsMT-COX1-sense probe (478051; ACD) or Mm-Mt-Cox1sense probe (530891; ACD), depending on the species, for 2 hours followed by the standard amplification steps as instructed by the manufacturer. These two probe sets are referred to as $\mathrm{Hs}-\mathrm{MT}$-COl sense and Mm-mt-Col sense, respectively, in this paper hereafter. Probes were diluted in RNAscope Probe Diluent and used at 1:200 for FFPE human tissues and cell blocks, and 1:300 for FFPE mouse tissues.

Fresh frozen sections were prepared and pretreated following the instructions of the manufacturer (ACD) for frozen tissues with the following modifications. Briefly, the tissues were fixed in pre-chilled $10 \% \mathrm{NBF}$ at $4^{\circ} \mathrm{C}$ for 15 minutes, dehydrated in an ethyl alcohol gradient, and then pretreated in hydrogen peroxide for 10 minutes at room temperature, steamed in pretreatment II for 5 minutes, and protease IV for 10 minutes at room temperature before being subjected to standard probe hybridization and signal amplification steps using RNAscope 2.5 HD Detection Kit (BROWN).

Whole slides were scanned using a Roche-Ventana DP200 (Roche, Pleasanton, CA) or a Hamamatsu Nanozoomer XR whole-slide scanner (Hamamatsu Photonics, Hamamatsu, Japan), and uploaded to Concentriq (Proscia, Philadelphia, PA) for whole-slide image viewing and micrograph documentation.

For HALO software version 2.4 (Indica Labs. Albuquerque, $\mathrm{NM}$ ) image analysis, the $\mathrm{Hs}-\mathrm{MT}$-COI sense probe was used at 1:200 dilution, and visualized by alcohol-soluble ImmPACT AEC Peroxidase (HRP) Substrate (SK-4205, Vector Laboratories, Burlingame, CA), mounted in aqueous medium (VectaMount AQ; H-5501; Vector Laboratories). After whole-slide scanning, coverslips were removed by soaking in $\mathrm{diH}_{2} \mathrm{O}$, and the residual mounting medium was washed away with fresh $\mathrm{diH}_{2} \mathrm{O}$. The polymerized AEC chromogenic in situ signals were then removed by washing in $100 \%$ ethanol, and these hematoxylin-only slides were mounted in Cytoseal 60 (8310-16; Thermo Fisher Scientific) and scanned again. Under these conditions, hematoxylin stains the entire cell including the cytoplasm. The ratio of the area of AEC-positive signals to total cellular area was used as the area-fraction of mtDNA signals. HALO software and its ISH v2.2 and area quantification v1.0 algorithms were used to analyze the images.

\section{In Situ Hybridization Validation}

DNase and RNase pretreatments were performed using the manufacturer's suggested protocol (ACD) with the following modifications. For DNase pretreatment, after steaming in pretreatment II, the slides were treated with 100 $\mu \mathrm{L}$ of DNase reaction buffer containing $10 \mu \mathrm{L}$ of DNase I reaction buffer $(10 \times), 1 \mu \mathrm{L}(2 \mathrm{U})$ of DNase I (M0303S; New England BioLabs, Ipswich, MA), and $89 \mu \mathrm{L}$ of nuclease-free water. The slides were then incubated at $37^{\circ} \mathrm{C}$ for 10 minutes, and washed in $\mathrm{diH}_{2} \mathrm{O} 3$ times, followed by in situ pretreatment III. Similarly, for RNase pretreatment, the slides were immersed in $50 \mu \mathrm{g} / \mathrm{mL}$ RNase A (EN0531, Thermo Fisher Scientific) diluted in $0.01 \mathrm{~mol} / \mathrm{L}$ Tris- $\mathrm{HCl}$ buffer, incubated at $37^{\circ} \mathrm{C}$ for 30 minutes, washed extensively in PBS with Tween-20 (PBST, P3563, 
MilliporeSigma) followed by in situ pretreatment II. Human $M T-C O 1$ sense probe was used at 1:200 dilution. Xenografts of human PC3 and VCaP prostate cancer cell lines were performed as described previously. ${ }^{39}$ Detection of mtDNA on mouse xenograft slides was performed using the CISH3,3'-diaminobenzidine (DAB) protocol as mentioned above. Both the mouse $\mathrm{Mm}-\mathrm{mt}-\mathrm{Col}$ sense probe and the human $\mathrm{Hs}$ $M T$-CO1 sense probe were used at 1:50 dilution.

Fluorescence in situ hybridization of mtDNA on FFPE tissues was conducted manually according to the manufacturer's protocols using RNAscope Multiplex Fluorescent Kit v2 (ACD).$^{38}$ Pretreatment and probe hybridization procedures remained the same as the one mentioned above for standard mtDNA CISH. During the signal amplification and development process, Opal Dyes (NEL741E001KT, NEL744E001KT, and NEL744E001KT; PerkinElmer, Waltham, MA) were used at 1:3500 in the TSA buffer provided in the RNAscope Multiplex Fluorescent Kit v2 for each probe. The slides were counterstained with DAPI, mounted in ProLong Gold Antifade Mountant (Thermo Fisher Scientific), and coverslipped.

Cultured adherent cells were prepared for RNAscope in situ hybridization using the manufacturer's instructions with the following modifications. CWR22Rv1 and PC3 cells were seeded on Nunc Lab-Tek II CC2 Chamber Slides (Thermo Fisher Scientific) at approximately 30,000 cells $/ \mathrm{cm}^{2} 2$ days before fixation. Cells were fixed for 30 minutes in $10 \% \mathrm{NBF}$, treated with hydrogen peroxide, steamed in pretreatment II solution for 5 minutes, and then incubated in protease III diluted 1:15 in PBS before proceeding to probe hybridization.

Localization of the mtDNA in situ signal was validated using a multiplex assay consisting of fluorescence in situ hybridization for mtDNA and immunofluorescence for a mitochondrial protein MRPL12. ${ }^{40,41}$ Briefly, LNCaP cells grown on chamber slides were fixed in formalin and pretreated as mentioned above for cells grown on chamber slides, and mtDNA fluorescence in situ hybridization was performed using the same protocol as for FFPE tissues. The slides were then incubated in MRPL12 primary antibody (HPA022853, MilliporeSigma) at 1:200 dilution in Antibody Dilution Buffer (ADB250, Roche, Switzerland) for $45 \mathrm{mi}-$ nutes at room temperature. Alexa Fluor 568 Goat anti-Rabbit $\operatorname{IgG}(\mathrm{H}+\mathrm{L})$ antibody (A-11036; Thermo Fisher Scientific) was used as secondary antibody at 1:300 dilution in PBS for 45 minutes at room temperature. The slides were counterstained, mounted, and then coverslipped in the same fashion as mentioned above for fluorescence in situ hybridization. Confocal fluorescent images were taken using a Zeiss AxioObserver inverted microscope with LSM700 confocal module (Carl Zeiss, Oberkochen, Germany) at the Johns Hopkins University School of Medicine Microscope Facility.

\section{Immunohistochemistry}

Chromogenic immunohistochemistry was performed mainly using the automated Ventana Discovery ULTRA (Roche). The slides were steamed for 32 minutes in $\mathrm{CC} 1$ buffer
(950-124; Roche) and incubated in the corresponding primary antibody at room temperature for 36 minutes. AntiMTCO1 antibody was used at 1:8000 dilution (ab14705; Abcam, Cambridge, MA) and anti-COX IV antibody was used at 1:8000 dilution (3E11, 4850; Cell Signaling Technology, Danvers, MA) as primary antibodies. The slides were developed using Discovery HQ HRP hapten-linked multimer detection kit (Roche).

\section{qPCR}

Total DNA from cell lines was extracted using the DNeasy Blood \& Tissue Kit (Qiagen, Hilden, Germany). qPCR was performed using TaqMan Universal Master Mix II, no UNG (4440043), and TaqMan Gene Expression Assays (Thermo Fisher Scientific) on a CFX Connect or a CFX96 Real-Time PCR Detection System (BioRad, Hercules, CA). The cycling conditions were: $95^{\circ} \mathrm{C}$ for 10 minutes, 40 cycles of $95^{\circ} \mathrm{C}$ for 15 seconds, $60^{\circ} \mathrm{C}$ for 1 minute, followed by melt curve analysis. The quantity of each amplified product was calculated using a standard curve of genomic DNA from peripheral blood leukocytes from a healthy donor (Catalog \# D1234148, Lot \# C210220, Biochain, Newark, CA). To calculate relative mtDNA copy number, $M T-C O l$ and $M T-N D 1$ genes were used as specific mitochondrial targets, and the beta globin locus transcript 3 (BGLT3) and complement 2 (C2) genes were selected to be the endogenous controls. TaqMan assays were purchased from Thermo Fisher Scientific. Information was as following: MT-CO1, Assay ID Hs02596864_g1, 4331182; $M T-N D 1 ;$ BGLT3, Assay ID Hs01629437_s1, 4331182; and C2, Assay ID Hs03599683_cn, 4400291. All qPCR reactions were performed in triplicate.

\section{Statistical Analysis and Data Reporting}

Statistical analyses were performed using GraphPad Prism software version 8 (GraphPad Software, La Jolla, CA). Pearson's correlation coefficient (Pearson's r) was used to investigate the relationship between two different qPCR assays for relative mtDNA copy number, and between mtDNA CISH and mtDNA copy number by qPCR. For all graphs, error bars represent the $\mathrm{SD}$, and in some cases were too small to be shown.

\section{Results}

Development and Validation of an in Situ mtDNA Copy Number Assay

Transcription of the circular mtDNA proceeds in both directions. Therefore, when targeting mtDNA by in situ hybridization, it is possible that probes will hybridize to either RNA or DNA, resulting in ambiguity in signal interpretation. However, most light strand transcripts are rapidly degraded, including those anti-sense to the $M T-C O 1$ gene. ${ }^{42,43}$ Thus, to minimize the potential of hybridization 
to mitochondrial RNA (mtRNA), an ACD probe set targeting the antisense region of the MT-COI gene (probe set referred to as $H s-M T-C O 1$ sense probe) was designed. The results of chromogenic in situ hybridization (DNAscope $\mathrm{CISH})$ using this probe set, in which highly intense DAB signals localize in a punctate distribution within the cytoplasm of an FFPE sample of human prostate cancer are shown (Figure 1). As a control during assay validation, pretreatment of slides with DNase I, but not with RNase A, abolished the signal (Figure 1). The same DNase I and RNase A pretreatment controls were performed on a number of different tissue samples using different probe concentrations (ranging from a probe set dilution of 1:50 to 1:200), and the results were the same (data not shown), confirming the specificity of the assay for DNA. To further validate the assay specificity, prostate cancer cells (CWR22Rv1 and PC3) were treated with ddC to reduce global mtDNA levels. ${ }^{44}$ The nucleotide derivative of ddC, ddCTP, can interact with and inhibit the activity of DNA polymerase gamma (pol $\gamma$ ), which is the only DNA polymerase in the mitochondria, and thus inhibit mtDNA replication. ${ }^{44-46}$ The results in which there was a ddC dose-responsive reduction in hybridization signals in both cell lines are shown (Figure 2).

To determine whether this in situ assay would provide a truly quantitative assessment of the mtDNA content, the mtDNA levels measured by CISH were correlated with mtDNA measurements by qPCR. As standards, PC3 and CWR22Rv1 cells were treated with a single dose of ddC for varying times. At each time point, cells were harvested and split into two portions. The first was prepared for formalin fixation and paraffin embedding, and the second was used for qPCR using the $M T-C O 1 \mathrm{mtDNA}$ locus normalized to the nuclear DNA gene, $B G L T 3$. In a second qPCR reaction, the mtDNA encoded $M T-N D 1$ gene that was normalized to a different nuclear gene $(C 2)$ was used. These two mitochondrial genes were chosen because they have been previously used to quantify mtDNA copy number. ${ }^{47,48}$
Figure $3 \mathrm{~A}$ shows a stepwise reduction in the ratio of mtDNA to nuclear DNA for each primer/probe set used for qPCR after treating cells for increasing times with ddC. The ratios of mtDNA/nuclear DNA content from these two sets of primer pairs were highly correlated (Figure 3B). Figure 4A shows a corresponding stepwise decrease in mtDNA in situ signals in relation to duration of drug treatment. Although both cell lines showed sharp reductions in mtDNA by both methods, in PC3 cells treated for 9 days, the mtDNA signals were largely undetectable by CISH (Figure 4A) and extremely low by qPCR (Figure 3). For image analysis, CISH was performed using the alcoholsoluble chromogenic substrate, AEC (Figure 4C). After hybridization and slide scanning, the chromagen (AEC) was dissolved in ethyl alcohol, and the slides were rescanned using the hematoxylin signals only (Figure 4C). The ratio of mtDNA area to total cellular area was determined using HALO software. There was a strong positive correlation between real-time qPCR and the area-fraction of mtDNA signals by image analysis (Figure 4B). To determine whether this assay could detect an increase in mtDNA levels in cells stimulated to increase mtDNA, as compared with their normal endogenous levels, DU145 cells were forced to overexpress MYC, which is known to stimulate an increase in mtDNA copy number. ${ }^{49}$ Supplemental Figure S1 shows an increase in the in situ signals for mtDNA in cells transduced with a lentiviral vector expressing human MYC, as compared with cells infected with an empty vector.

When mtDNA is depleted, the mtDNA-encoded mRNAs and proteins will also be greatly reduced. ${ }^{27,50}$ The loss of mtDNA was accompanied by a marked reduction of the mtDNA encoded protein MT-CO1 in a time-dependent manner in response to ddC treatment, whereas the nuclear DNA-encoded COX-IV protein remained present as expected (Supplemental Figure S2).

The sequence identity between human mtDNA and mouse mtDNA in the targeted regions of the MT-COI gene is $77.8 \%$. A prior study using RNAscope technology

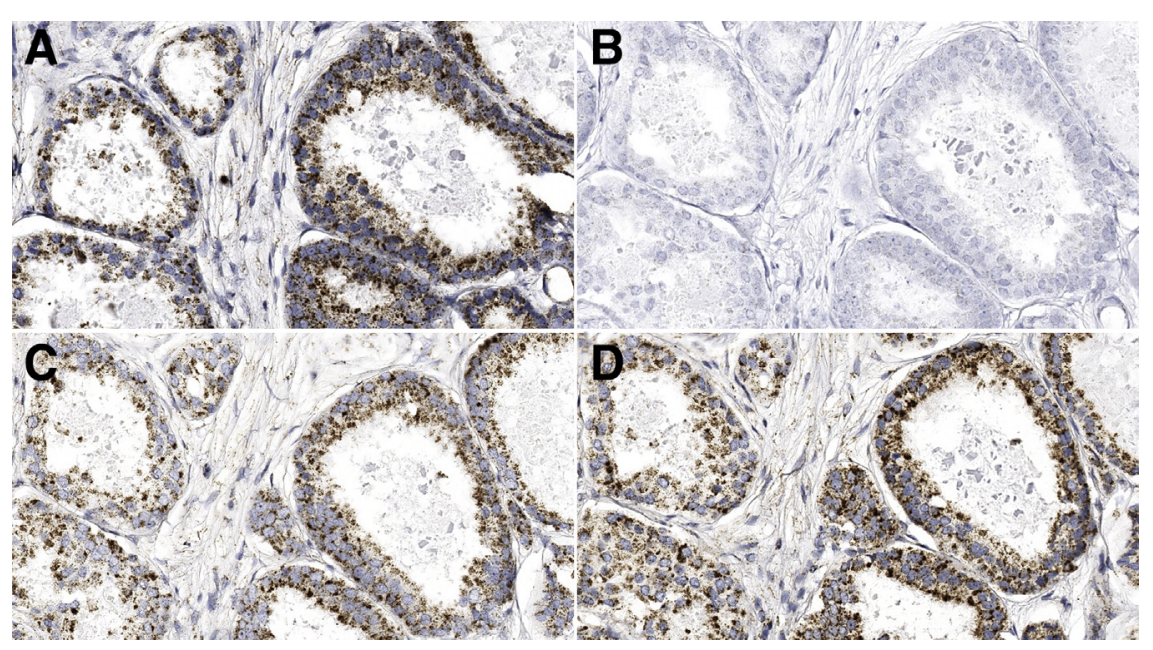

Figure 1 In situ assay specificity verified by DNase pretreatment. mtDNA in situ hybridization assay on formalin-fixed, paraffin-embedded (FFPE) prostate tissues without DNase I (A), with DNase I (B), without RNase A (C), and with RNase A (D) pretreatments. The tissues were hybridized with human Hs-MT-CO1 sense probe and visualized with $D A B$ chromogen. Original magnification, $\times 400$ (A-D). 

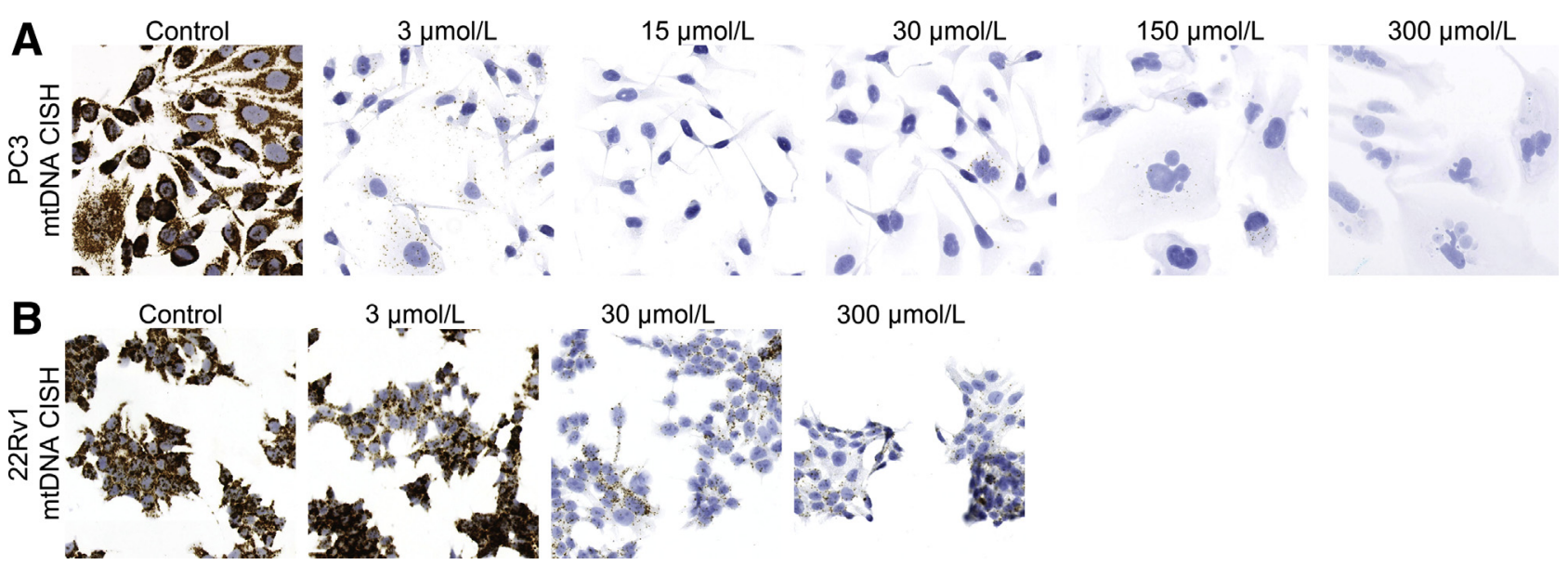

$\mathrm{mo \textrm {mol } / \mathrm { L }}$

Figure 2 Dose-dependent stepwise reduction in hybridization signals after forced reductions in mtDNA by $2^{\prime}, 3^{\prime}$-dideoxycytidine (ddC) in PC3 (A) and

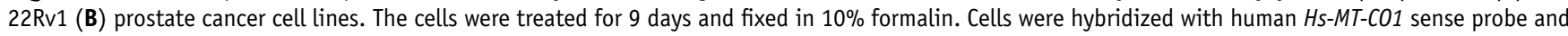
visualized with DAB chromogen. Original magnification, $\times 200$ (A and B). CISH, chromogenic in situ hybridization.

to distinguish mouse and human gene expression at the RNA level showed that for probe sets with $<80 \%$ homology, the probes did not cross hybridize. ${ }^{51}$ Therefore, the specificity of the hybridization was further tested using human cancer cells grown as xenografts in mice. Hybridization signals for the human $\mathrm{MT}$-COI sense probe set were observed exclusively in the human tumor cells, but not in the mouse stromal cells (Supplemental Figure S3). Conversely, a probe set developed to the mouse $\mathrm{mt}$-Col gene antisense region (termed $\mathrm{Mm}$ - $\mathrm{mt}$-Col sense probe) showed signals only in the mouse stromal cells and not in the human cells in the adjacent slide (Supplemental Figure S3). This result is consistent with the high specificity of these DNAscope hybridization reactions. $^{38,51,52}$
To verify whether the in situ signals were localized to mitochondria, a fluorescence approach was used for in situ hybridization combined with immunofluorescence against MRPL12, a well-known mitochondrial protein..$^{40,41,53}$ As visualized by confocal microscopy (Supplemental Figure S4), the punctate signals for mtDNA and MRPL12 protein showed prominent areas of overlap in the cytoplasm, consistent with mitochondrial localization.

mtDNA Copy Number Survey of Normal Tissues by in Situ Hybridization

Cellular and tissue heterogeneity of mtDNA copy number is poorly explored. mtDNA CISH was applied to various tissues from mice and humans. As an example of marked
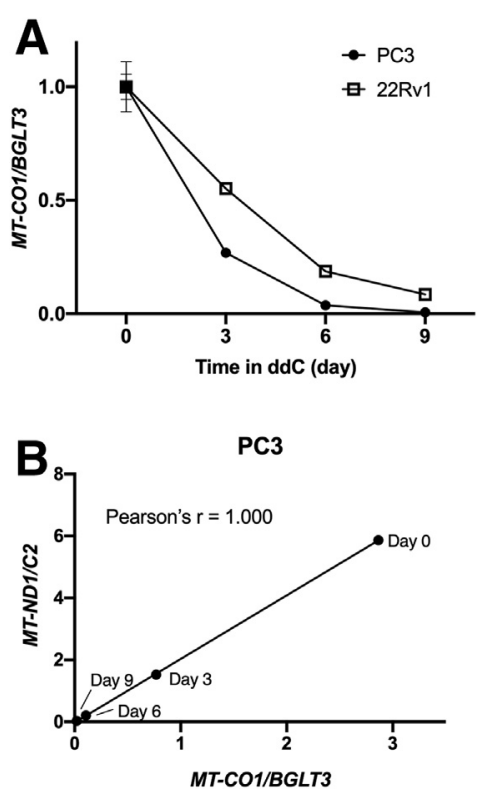

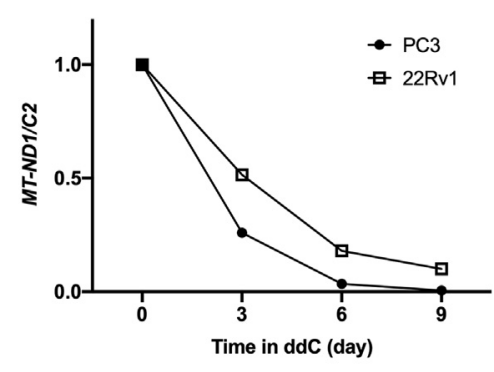

22Rv1

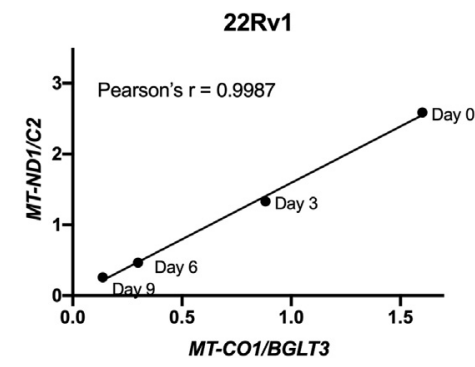

Figure 3 Time-dependent reduction in mtDNA copy number measured by quantitative PCR ( $(\mathrm{PCR})$ in prostate cancer cell lines treated with $2^{\prime}, 3^{\prime}$-dideoxycytidine (ddC). $\mathrm{ddC}$ concentration: $3 \mu \mathrm{mol} / \mathrm{L}$ for $\mathrm{PC} 3,30 \mu \mathrm{mol} / \mathrm{L}$ for 22Rv1. A: Stepwise reduction in the ratio of mtDNA to nuclear DNA for two different primer/probe sets. Fold differences are shown and were determined by defining the ratio of mtDNA gene to nuclear DNA gene in day 0 cells as 1.0. B: The ratios of mtDNA/nuclear DNA content from these two sets of primer pairs were highly correlated ( $P<0.005$ for both correlations). Relative standard curve method was used to calculate the quantity of each amplified product. All qPCR reactions including the standard curve were performed in triplicate. Data are expressed as means \pm SD. 
A
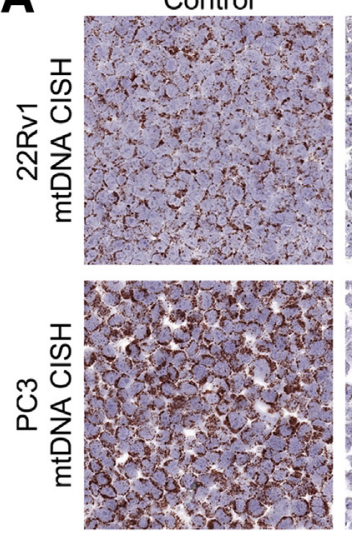

B

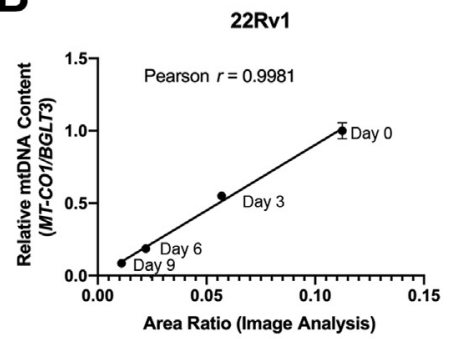

22Rv1
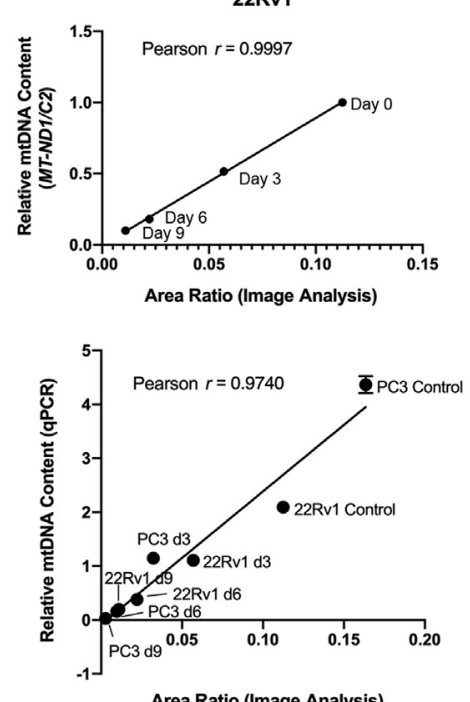

Area Ratio (Image Analysis)
Day 9
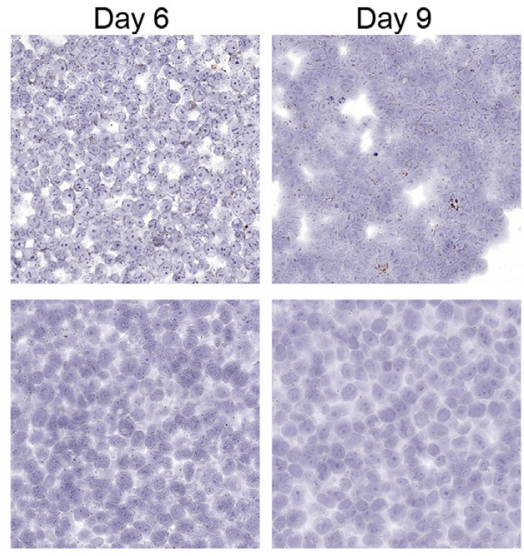

Day 3

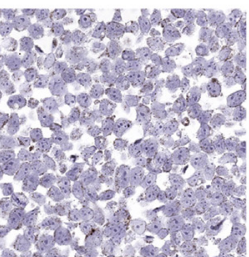

PC3

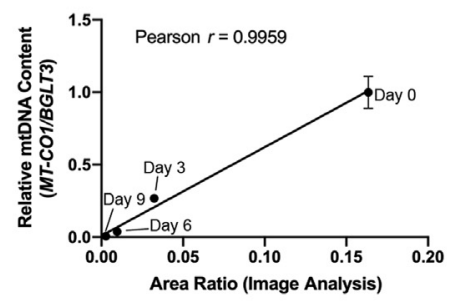

PC3

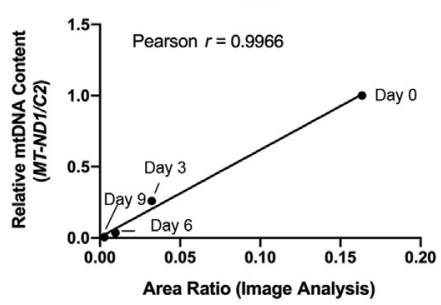

C

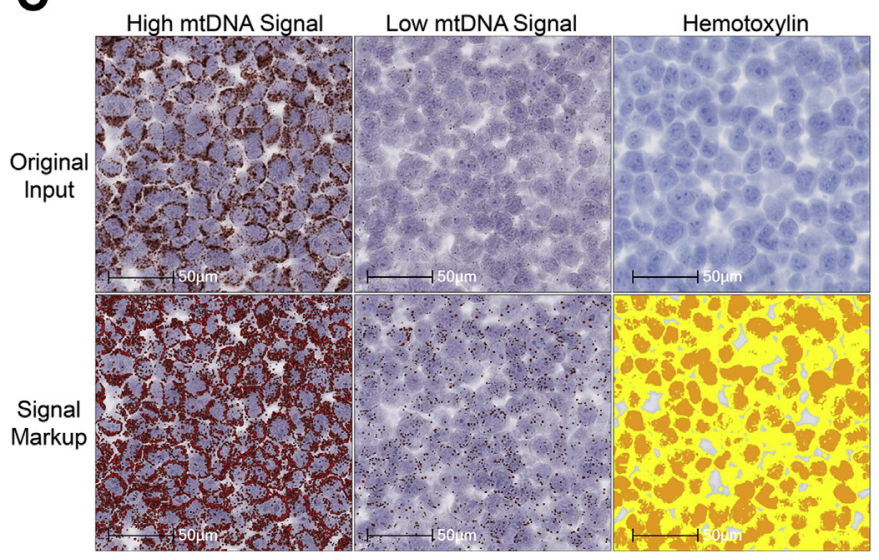

Figure 4 Quantitative nature of the in situ assay for mtDNA copy number determined by strong positive correlation between quantitative PCR ( $q P C R$ ) and the area-fraction of mtDNA signals by image analysis. A: Stepwise decrease in mtDNA in situ signals in relation to duration of $2^{\prime}, 3^{\prime}$ dideoxycytidine ( $\mathrm{ddC}$ ) treatment in formalin-fixed, paraffin-embedded (FFPE) cell blocks. Cells were hybridized with human $\mathrm{Hs}-\mathrm{MT}$-CO1 sense probe and visualized with AEC chromogen. B: Correlations between the relative mIDNA content by qPCR and by area-fraction using HALO software. For the top four graphs, the fold differences are shown and were determined by defining the ratio of mtDNA gene to nuclear DNA gene in day 0 cells as $1.0(P$ $<0.005$ for both correlations). C: Example of HALO markup images for image analysis. To illustrate the range of staining signals that HALO can detect, two image examples are shown here, one with a high mtDNA signal, and another with a low mtDNA signal. Signal markup refers to a false color highlight of the image analysis result. Data are expressed as means \pm SD. Scale bars: $50 \mu \mathrm{m}(\mathbf{C})$. Original magnification: $\times 400($ A); $\times 630$ (C). $\mathrm{CISH}$, chromogenic in situ hybridization. 

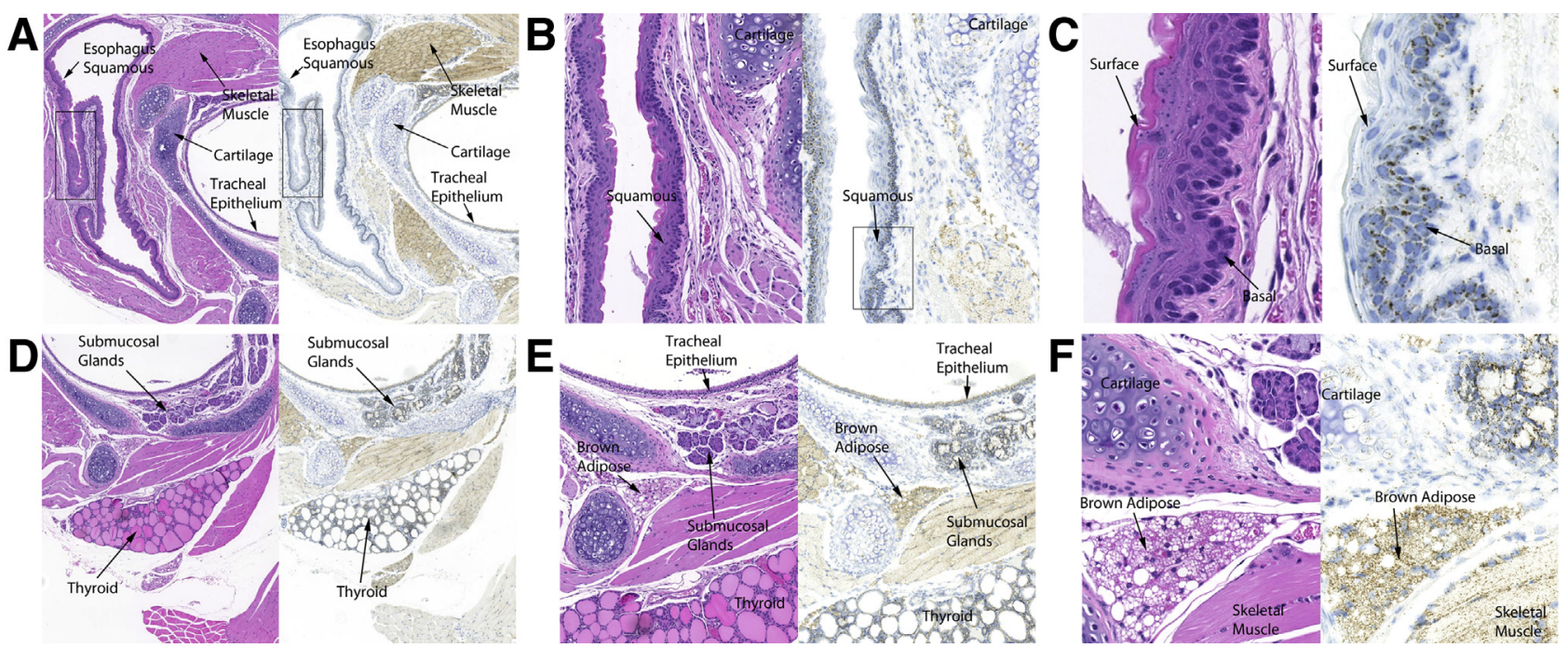

Figure 5 Each panel shows a hematoxylin and eosin image (left) and chromogenic mtDNA in situ hybridization (right) of the neck region from a 2month-old female FVB/N mouse. A-C: Strong mtDNA signals are present in the basal compartment of squamous epithelium in the esophagus. Very low hybridization signals are seen in tracheal cartilage. B and $\mathbf{C}$ show the boxed areas in A and B, respectively, at higher magnification. D-F: Skeletal muscle, glandular tissues including the tracheal epithelium, submucosal glands, and thyroid, as well as brown adipose tissue also show very high levels of mtDNA signals. In the CISH images, the tissues were hybridized with mouse Mm-mt-Co1 sense probe and visualized with DAB chromogen. Original magnification: $\times 40$ $(\mathbf{A}$ and $\mathbf{D}) ; \times 120(\mathbf{B}) ; \times 400(\mathbf{C}) ; \times 70(\mathbf{E}) ; \times 200(\mathbf{F})$. CISH, chromogenic in situ hybridization.

tissue/cell-type heterogeneity, Figure 5 shows a cross section from the neck region of a mouse encompassing a range of normal tissues. Strong mtDNA signals were present in the basal and suprabasal cell layers (Figure 5) (see Results regarding stem cell compartments) of squamous epithelium in the esophagus, as well as in skeletal muscle, and glandular tissues including the tracheal epithelium, submucosal glands, and thyroid (Figure 5). Very low hybridization

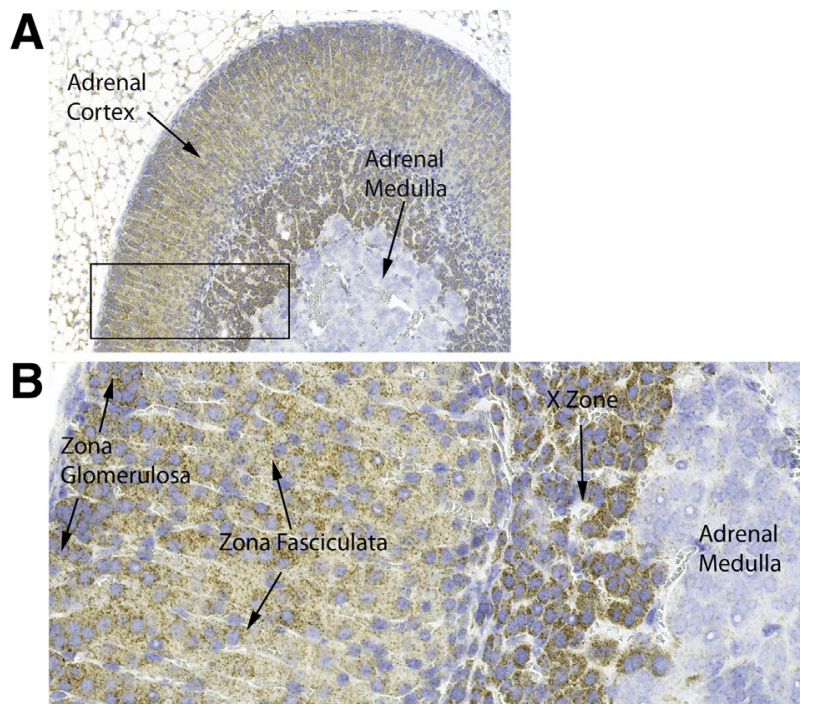

Figure 6 Cross section of an adrenal gland from a 2-month-old female FVB/N mouse. A: The adrenal medulla shows much lower mtDNA signals than the cortex. The cortex shows variation in different zones with prominent in situ signal in the X-zone. B: The boxed area in $\mathbf{A}$ is shown at higher magnification. The tissues were hybridized with mouse Mm-mt-Co1 sense probe and visualized with $D A B$ chromogen. Original magnification: $\times 100$ (A); $\times 400$ (B). signals were seen in tracheal cartilage (Figure 5), consistent with its known lack of internal blood vessels and low mitochondrial mass. Brown adipose tissue (Figure 5) showed very high levels of mtDNA signals, in line with the well-known high levels of mitochondria in this tissue, compared with white adipose tissue. ${ }^{54-56}$ Salivary glands showed a pattern in which the ducts showed higher mtDNA signals compared with the acini (not shown).

As expected, relatively high levels of mtDNA hybridization signals were found in cardiac muscle tissue, commensurate with their high energy demands and known high mitochondrial mass (not shown). In the pancreas, the islets showed more mtDNA signals than the exocrine acini (not shown). This corresponds to the observations of higher mitochondrial protein expression in pancreatic islets versus acini. ${ }^{57}$ In the urinary bladder, there were strikingly high levels of mtDNA signals in umbrella cells in female mice, as compared with the underlying intermediate or basal cells, which were higher than the detrusor muscle and other mesenchymal tissues (Supplemental Figure S5).

\section{Adrenal Gland}

The mouse adrenal gland showed marked differences in mtDNA signals by zone. In the cortex, there appeared to be a slight gradation of signals, with somewhat stronger signals toward the capsule in the zona glomerulosa, and a tapering of signals in the zona fasciculata toward the medulla (Figure 6). Mice do not have a zona reticularis,${ }^{58}$ but in female mice, the X-zone showed higher levels of mtDNA than the zona fasciculata. Strikingly, the adrenal medulla showed much lower mtDNA signals than the cortex 


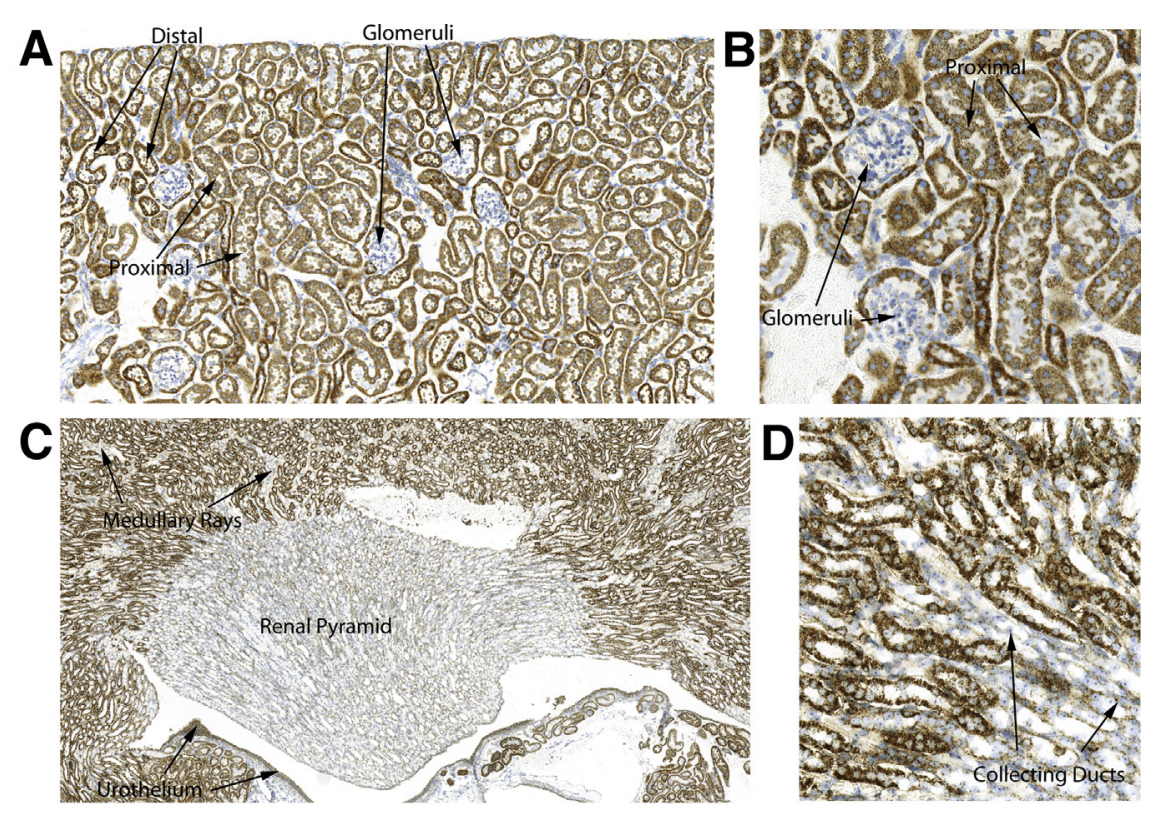

Figure 7 Cross section of a kidney from a 2-month-old male FVB/N mouse. A and B: Very low hybridization signal levels are present in the glomeruli. Epithelial cells in distal convoluted tubules show higher mtDNA signals than those in proximal tubules. C and D: Collecting ducts in medullary rays and in the medulla show notably reduced mtDNA hybridization signals. The tissues were hybridized with mouse $M m-m t-C o 1$ sense probe and developed with $D A B$ chromogen. Original magnification: $\times 100(\mathbf{A}) ; \times 200(\mathbf{B}$ and $\mathbf{D})$; $\times 40$ (C).

(Figure 6) in both males and females, which is consistent with prior results by $\mathrm{qPCR} .{ }^{59}$

\section{Kidney}

In the mouse kidney, robust signals were found in cortical tubular epithelial cells and strikingly low signal levels in cells within glomeruli (Figure 7). Distal convoluted tubular epithelium showed stronger signals than in proximal tubules. In collecting ducts, present in the cortex in medullary rays, and in the medulla, there were markedly reduced mtDNA hybridization signals compared with proximal and distal tubules. A highly similar pattern in human kidney tissues was found (not shown). As an additional control for hybridization efficiency in the different renal parenchymal compartments, DNA in situ hybridization for telomeres was performed using a highly similar chromogenic approach. ${ }^{35,60}$ Similarly strong telomeric DNA signals were found in glomeruli as well as throughout the different renal tubules, supporting the likelihood that lower levels of mtDNA signals are not related to failure of probe penetration (not shown).

\section{Liver}

In the mouse liver, there was a striking zonal distribution to mtDNA hybridization signals such that periportal hepatocytes (zone 1) showed the highest levels, with an apparent gradient of lower levels toward the hepatocytes surrounding the central veins (zone 3) (Figure 8). This result is consistent with a recent study by Brosch et $\mathrm{al}^{21}$ who examined nextgeneration DNA sequencing data for mtDNA after laser capture microdissection of different human liver zones. Although the question of liver stem cells was not examined, it would appear that if hepatocytic stem cells display similar properties to those in the self-renewing tissues that show clear hierarchical differentiation (eg, see below results regarding squamous and intestinal epithelia), then it is likely that only the putative stem cells near the portal triads (Sox9 positive), ${ }^{61}$ and not those located around the central veins (Axin2 positive), ${ }^{62}$ are behaving in this manner.

\section{Self-Renewing Tissues with Stem Cell Compartmentalization}

Based on the findings above in the esophagus (Figure 5), mtDNA CISH was performed in other continuously selfrenewing tissues containing hierarchical differentiation, starting with other stratified squamous epithelia. In each stratified squamous tissue examined, including mouse skin, cervix, vagina, oropharynx, and esophagus, the cells in the basal and suprabasal compartments showed higher mtDNA signals than cells toward the surface (Supplemental Figure S6). Because higher levels of in situ signals were seen in both the basal and suprabasal cell layers, these results suggest that both stem cells and transient amplifying cells contain higher levels of mtDNA than more differentiated cells in squamous epithelia. In mouse hair follicles, those that are in the anagen growth phase showed intense signals in the deepest regions, with a gradation of signals toward the skin surface (Supplemental Figure S7). Also, these anagen phase regions showed considerably higher mtDNA signals compared with those in telogen phase (Supplemental Figure S7). This result agrees with previous studies showing higher mitochondrial activity by MitoTracker (Thermo Fisher Scientific) in anagen cells than telogen cells. ${ }^{63}$ In the gastrointestinal tract, the human (Figure 9A) and mouse small intestine showed more 


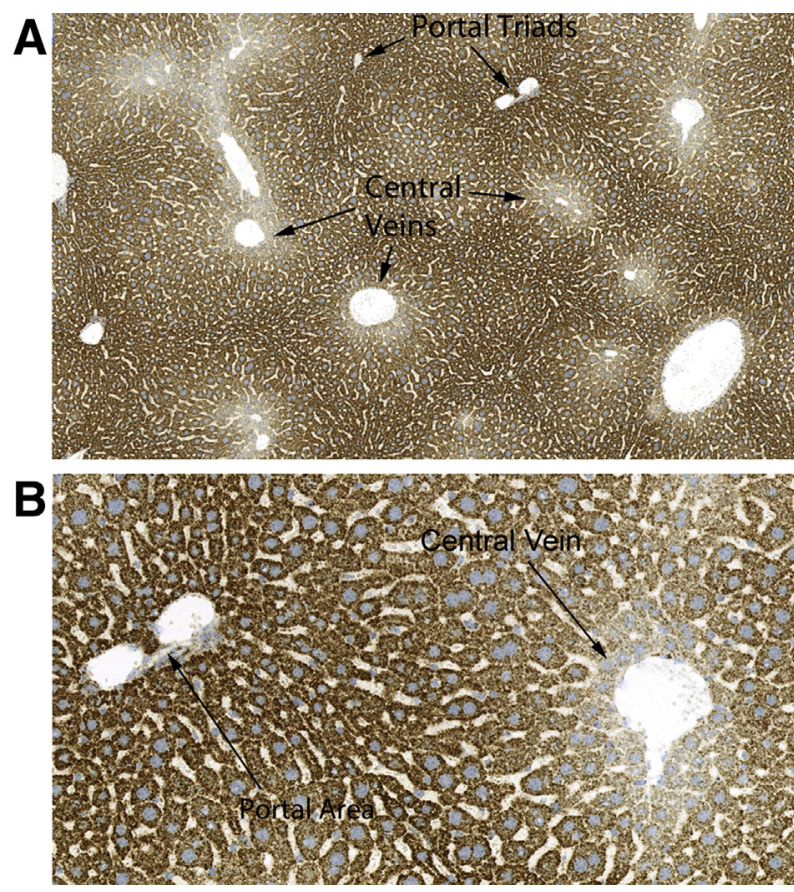

Figure 8 Cross section of liver from a 2-month-old male FVB/N mouse. A: There is a zonal distribution to mtDNA hybridization signals such that higher levels are present in the periportal hepatocytes and lower levels in the pericentral ones. B: A higher magnification image of $\mathbf{A}$ is shown. The tissues were hybridized with mouse $\mathrm{Mm}-\mathrm{mt}$-Co1 sense probe and developed with $D A B$ chromogen. Original magnification: $\times 70($ A); $\times 230$ (B).

mtDNA signals in the crypts, where the stem cells and transient amplifying/proliferative compartment cells are located, compared with the villus tips (Figure 9A). Telomere CISH experiments were performed on adjacent slides to rule out the possibility that lower levels of mtDNA in situ hybridization signals in the villus tips were due to failure of probe penetration (Figure 9A). A similar pattern was present in the colon of both mouse and human, and mouse stomach, where the stem/proliferative cells in the isthmus showed higher mtDNA signals than the surface or deeper glands (Figure 9B). Therefore, in each rapidly self-renewing tissue type that is organized using hierarchical differentiation, the stem cell/proliferative cell compartments contain higher mtDNA signals compared with the more differentiated cells.

\section{Male Reproductive Tissues}

In the prostatic epithelium, basal cells contained increased signals in general as compared with luminal cells (Supplemental Figure S8), and the epithelium showed overall higher signals than the stroma. The higher mtDNA content in the basal cell layer might be due to the fact that MYC is almost exclusively expressed in the basal cells, ${ }^{49,64,65}$ and MYC has been shown to regulate mtDNA levels previously, ${ }^{49}$ and in prostate cancer cell lines (Supplemental Figure S1), raising the question that mtDNA levels in some tissues are physiologically regulated by MYC (Discussion). In the seminiferous tubules of the testis, strong signals were observed in germ cells adjacent to the basement membrane with an overall decrease in signals as cells differentiated toward mature sperm in the lumens (Supplemental Figure S9), which is consistent with prior studies. ${ }^{66,67}$ In the epididymis, there were more mtDNA signals in the caput epithelium as compared with epithelium in the initial segment (Supplemental Figure S9).

\section{Female Reproductive Tissues}

The epithelium in mouse fallopian tube and uterus had strong mtDNA in situ signals (Supplemental Figure S10). In the mouse ovary, in regions containing follicles, there were very strong signals in the granulosa cells directly surrounding the oocytes, with many, albeit less numerous, signals in the oocyte cytoplasm. In addition, immature corpora lutea showed higher mtDNA signals compared with the mature corpora lutea (Supplemental Figure S10). Mouse epithelial cells in the endometrium showed clearly higher mtDNA signals as compared with endometrial stroma (Supplemental Figure S10).

\section{Central Nervous System}

In the central nervous system, neuronal cell bodies generally contained much stronger signals than surrounding glial cells and white matter. Supplemental Figure S11 illustrates this in the mouse cerebellum, which shows strong signals in Purkinje cell neuronal cell bodies and in neuronal cell bodies within a deep cerebellar nucleus.

\section{Aging Kidney and Calorie Restriction}

Kidney function is known to decrease gradually with increasing age in mammals, which has been associated with a gradual decline in mitochondrial function. ${ }^{68-70} \mathrm{~A}$ recent study found that the ratio of mtDNA to nuclear DNA decreased in the aging mouse kidney. ${ }^{37}$ Further, this reduction was prevented by calorie restriction, which is consistent with the finding that calorie restriction can prevent age-related declines in mitochondrial biogenesis and function in the kidney. ${ }^{37}$ However, which compartments in the kidney are most affected by these changes were not explored. Therefore, the effects of aging and calorie restriction on mouse mtDNA levels were examined in the kidney using their in situ assay. Mice were either fed ad libitum or treated with calorie restriction and then aged to 24 months. Tissue sections from the mouse kidneys were hybridized for mtDNA. After whole-slide scanning and blinding of the slides, a visual microscopic review was conducted by two separate observers. Using this blind review, each observer (A.M.D.M and A.Z.R) separated the mice into two groups. One group of 3 mice contained variably lower levels of mtDNA in all tubule compartments by visual estimate (Figure 10 shows cortical tubules) and was composed of the aging mice fed ad libitum. Although a 

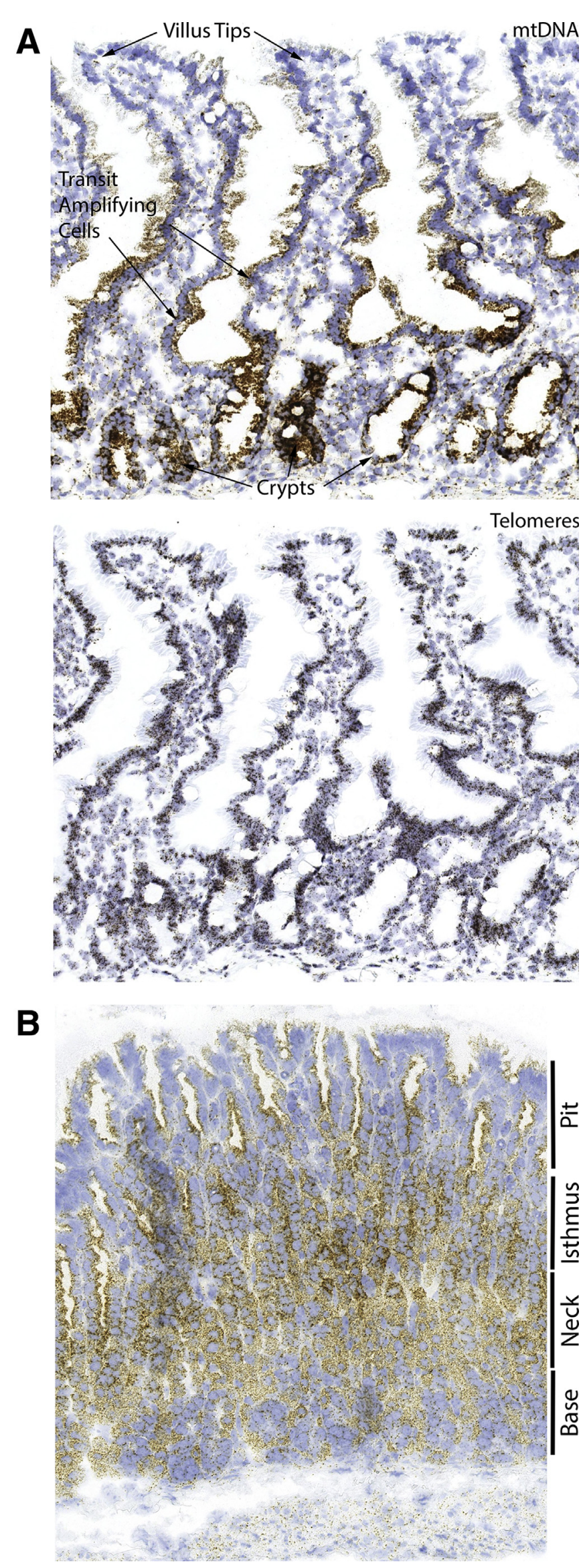

general reduction in mtDNA signals was present throughout the kidney, in some of the cortical tubules, there were markedly reduced signals, and this was only seen in the $a d$ libitum-fed older mice (Figure 10). The other group $(n=$ 6 ), which did not show these isolated areas of markedly reduced mtDNA signals, consisted of a combination of younger mice fed ad libitum, and aged calorie-restricted mice; these two treatment groups were visually indistinguishable.

\section{Discussion}

There is no gold standard for measuring cell-type heterogeneity in mtDNA copy number in tissue samples. This study presents a novel approach that is widely applicable, straight-forward to implement, and can be used either qualitatively or quantitatively. A key finding using this approach, that was not previously appreciated, is that in tissues organized into self-renewing hierarchical stem cell-driven differentiation systems, ${ }^{71}$ cells within stem cell/ proliferative compartments contain higher mtDNA levels compared with their more differentiated progeny. This finding raises a number of important questions. The first involves our understanding of mtDNA replication. Although it is known that mtDNA replication is uncoupled from cell-cycle progression (eg, nuclear DNA replication) in some mitotic and post-mitotic cells, ${ }^{72,73}$ a number of groups have shown mtDNA replication appears to be synchronized during the cell cycle in cell culture systems. ${ }^{31-33,74}$ Thus, the findings to date are somewhat contradictory. Future studies using an in situ approach, coupled with the ability to visualize newly synthesized mtDNA and nuclear DNA in intact tissues, can help clarify this question.

Another question is how mtDNA levels are regulated in the self-renewing tissues described herein. Key regulators of mtDNA replication are peroxisome proliferator activated receptor coactivator 1 alpha (PGC1-a; encoded by $P P A R G C 1 A)$ and peroxisome proliferator activated receptor coactivator 1 beta (PGC-1 $\beta$; encoded by PPARGC1B). Further, MYC has been shown to drive mtDNA replication and mitochondrial biogenesis. ${ }^{49}$ Interestingly, in the intestine $^{75}$ and squamous epithelia, ${ }^{76}$ MYC levels are highest in regions that clearly overlap with those with the highest

\footnotetext{
Figure 9 In situ hybridization staining of $\mathrm{mtDNA}$ and telomeres on frozen human duodenum and mtDNA on formalin-fixed, paraffin-embedded mouse stomach. A: Epithelial cells in the crypts and transit/amplifying cell compartments have higher mtDNA in situ signals than those in the villus tips (top panel); telomeric DNA in situ hybridization on an adjacent slide served as a tissue quality control (bottom panel). Strong telomeric DNA signals are seen through the bottom of the crypts to the top of the villus. The tissues were hybridized with human Hs-MT-CO1 sense probe and Hs-TELO-01 probe, respectively, and visualized with DAB chromogen. B: Representative staining of mtDNA in the stomach from a 3-month-old male FVB/N mouse. The stem/proliferative cells in the isthmus shows higher mtDNA signals than the surface or deeper glands. The tissues were hybridized with $M m-m t-C o 1$ sense probe and visualized with DAB chromogen. Original magnification: $\times 100($ A) $; \times 200$ (B).
} 

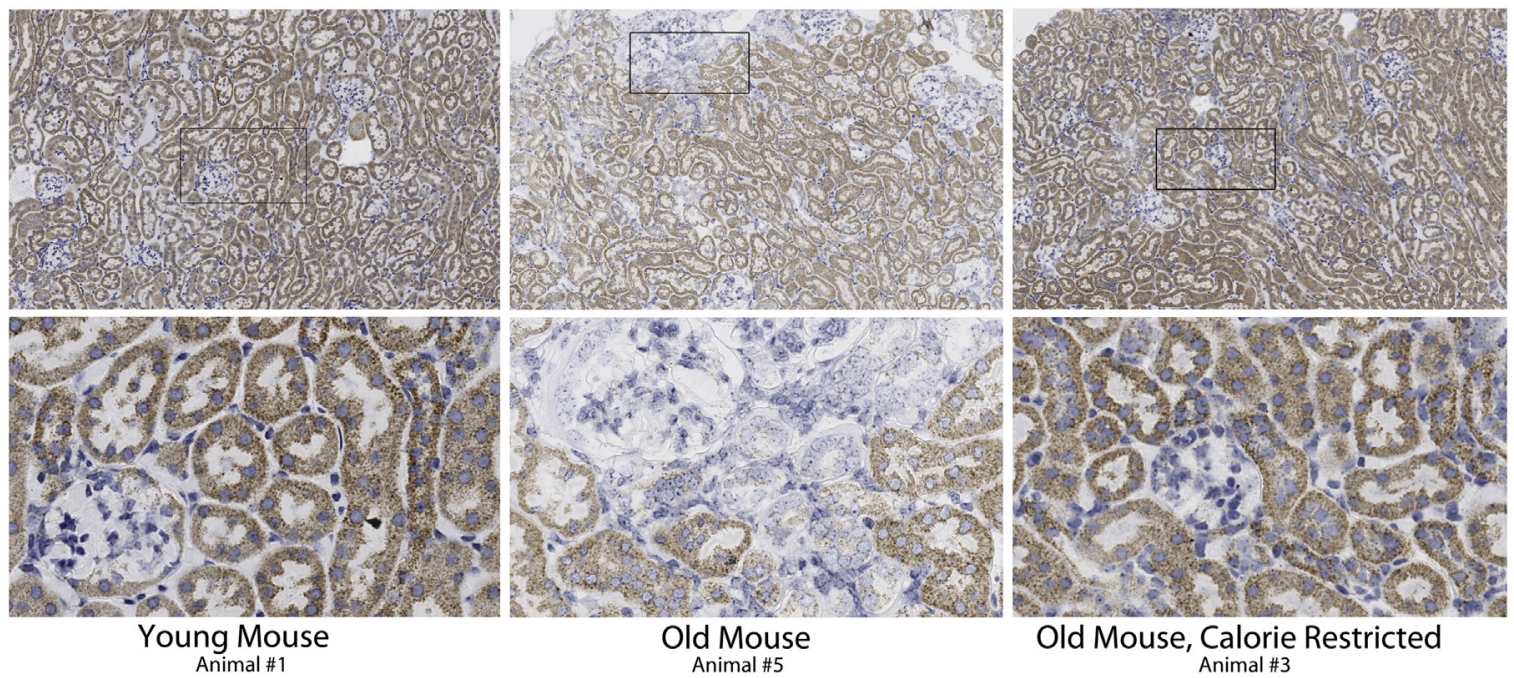

Figure $10 \mathrm{mtDNA}$ in situ hybridization in kidneys from young, aging, and aging with calorie restriction C57BL/6 mice. In the aging mouse kidney, decreased mtDNA levels are seen in tubules, which is prevented by calorie restriction. The tissues were hybridized with mouse $M m-m t$-Co1 sense probe and visualized with DAB chromogen. Boxed areas in the top row are shown at higher magnification in the bottom row. $n=3$ (each group of mice). Original magnification: $\times 100$ (top row); $\times 400$ (bottom row).

mtDNA levels, raising the possibility that physiological regulation of mtDNA during tissue renewal in many stem cell compartments is governed, at least in part, by MYC. In fact, in mice with targeted disruption of Myc in the intestine, Myc-deficient crypts are lost, and Myc is required for successful progression through the cell cycle. ${ }^{75}$ It is possible, therefore, that one mechanism by which Myc functions in the intestine is to induce mtDNA replication and mitochondrial biogenesis. Future studies are needed to address the question regarding the regulation of mtDNA levels in normal self-renewing tissues by MYC. Other genes related to mitochondrial function also appear to be required for intestinal stem cell maintenance because mice with targeted disruption of the key mitochondrial protein chaperone, hsp60, show loss of stem cells and proliferative capacity. ${ }^{77}$ Another question is why prior studies have not shown the stark differences observed here in stem/proliferative compartments in mtDNA levels. ${ }^{77}$ Immunohistochemistry are currently being performed against a number of mitochondrial enzymes and in situ hybridization for mtRNAs to gain further insights. Preliminary findings in the human intestine indicate that mitochondrial protein markers do not correlate with mtDNA levels, but that 12S rRNA (MT-RNRI) does.

In the kidney of young healthy mice and humans, striking differences in mtDNA levels within different renal epithelial compartments were observed. First, much lower levels of mtDNA were verified in virtually all cell types present within the glomeruli. ${ }^{28}$ Interestingly, distal tubules showed higher mtDNA levels than proximal tubules, and collecting ducts showed markedly lower levels than proximal or distal tubules. Prior studies have shown a reduction in mtDNA to nuclear DNA by PCR-based assays in aging mouse kidney tissues, and this could be prevented by calorie restriction, ${ }^{37}$ treatment with a dual agonist of the farnesoid $\mathrm{X}$ receptor (FXR), and the
G protein-coupled receptor TGR4, INT- $767,{ }^{37}$ or the estrogen-related receptors ERR $\alpha, \operatorname{ERR} \beta$, and ERR $\gamma{ }^{70}$ Consistent with this, in the present study, the marked reduction in mtDNA levels was visualized in a number of tubule compartments and was prevented by calorie restriction. The current in situ approach will be useful to determine whether similar changes are seen in the human kidney with aging and how mtDNA levels are altered in different renal pathologies.

Another interesting finding was the remarkable zonal differences in mtDNA numbers in hepatocytes that is quite consistent with the known oxygen gradient, as well as a recent study using next-generation sequencing from lasercapture microdissected zones of the liver. ${ }^{21}$

The ability to routinely interrogate mtDNA levels at the cellular level in the context of normal and abnormal spatial organization of cell types should greatly facilitate approaches to deciphering changes that occur in mtDNA in a number of disease states, including different cancers, ${ }^{78}$ their precursor lesions, and a large spectrum of non-neoplastic clinical disorders. These include inherited autosomal and mtDNA syndromes that affect mtDNA copy number ${ }^{79}$ that involve a number of organ systems and cell types (eg, involving skeletal and cardiac muscle, neurons in Parkinson's disease and other neurodegenerative disorders, hepatocytes in liver, etc.). In situ studies of the involved tissues using the current approach can facilitate novel insights into disease pathogenesis and response to therapies.

In summary, the authors present a novel, quantitative, and straightforward approach to mtDNA-level measurements in tissue samples. This approach provides the first widely available opportunity to test changes that occur in mtDNA copy number in specific cell types, while retaining spatial information. The current study uncovered evidence of increased mtDNA copy number in stem/proliferative 
compartments throughout the body and serves as an initial phase toward the completion of a comprehensive cellular atlas of mtDNA copy number across tissues, and changes in such cell types in aging and disease. It should complement approaches using genomic methods, such as those using single-cell RNA-seq and ATAC-Seq in which several largescale efforts are underway. It can also complement other in situ approaches such as spatial transcriptomics, highplex immunohistochemistry and in situ hybridization, and prove useful in studies related to the effects of genotype, environmental exposures, and interventions (eg, dietary or exercise) in model systems and humans.

\section{Acknowledgments}

We thank Daniel Monaco and Peter Chianchiano for helping to set the foundation of this work.

\section{Supplemental Data}

Supplemental material for this article can be found at http://doi.org/10.1016/j.ajpath.2020.03.018.

\section{References}

1. Gorman GS, Chinnery PF, DiMauro S, Hirano M, Koga Y, McFarland R, Suomalainen A, Thorburn DR, Zeviani M, Turnbull DM: Mitochondrial diseases. Nat Rev Dis Primers 2016, 2: 16080

2. Taylor RW, Turnbull DM: Mitochondrial DNA mutations in human disease. Nat Rev Genet 2005, 6:389-402

3. Meyer JN, Hartman JH, Mello DF: Mitochondrial toxicity. Toxicol Sci 2018, 162:15-23

4. Larsson N-G: Somatic mitochondrial DNA mutations in mammalian aging. Annu Rev Biochem 2010, 79:683-706

5. Ashar FN, Moes A, Moore AZ, Grove ML, Chaves PHM, Coresh J, Newman AB, Matteini AM, Bandeen-Roche K, Boerwinkle E, Walston JD, Arking DE: Association of mitochondrial DNA levels with frailty and all-cause mortality. J Mol Med 2015, 93:177-186

6. Sun N, Youle RJ, Finkel T: The mitochondrial basis of aging. Mol Cell 2016, 61:654-666

7. Ashar FN, Zhang Y, Longchamps RJ, Lane J, Moes A, Grove ML, Mychaleckyj JC, Taylor KD, Coresh J, Rotter JI, Boerwinkle E, Pankratz N, Guallar E, Arking DE: Association of mitochondrial DNA copy number with cardiovascular disease. JAMA Cardiol 2017, 2:1247-1255

8. Kauppila TES, Kauppila JHK, Larsson N-G: Mammalian mitochondria and aging: an update. Cell Metab 2017, 25:57-71

9. Clay Montier LL, Deng JJ, Bai Y: Number matters: control of mammalian mitochondrial DNA copy number. J Genet Genomics 2009, 36:125-131

10. Barazzoni R, Short KR, Nair KS: Effects of aging on mitochondrial DNA copy number and cytochromec oxidase gene expression in rat skeletal muscle, liver, and heart. J Biol Chem 2000, 275:3343-3347

11. Cree LM, Patel SK, Pyle A, Lynn S, Turnbull DM, Chinnery PF, Walker M: Age-related decline in mitochondrial DNA copy number in isolated human pancreatic islets. Diabetologia 2008, 51: $1440-1443$

12. Miller FJ, Rosenfeldt FL, Zhang C, Linnane AW, Nagley P: Precise determination of mitochondrial DNA copy number in human skeletal and cardiac muscle by a PCR-based assay: lack of change of copy number with age. Nucleic Acids Res 2003, 31:e61

13. Kaaman M, Sparks LM, van Harmelen V, Smith SR, Sjölin E, Dahlman I, Arner P: Strong association between mitochondrial DNA copy number and lipogenesis in human white adipose tissue. Diabetologia 2007, 50:2526-2533

14. Masuyama M, Iida R, Takatsuka H, Yasuda T, Matsuki T: Quantitative change in mitochondrial DNA content in various mouse tissues during aging. Biochim Biophys Acta 2005, 1723:302-308

15. Kazachkova N, Ramos A, Santos C, Lima M: Mitochondrial DNA damage patterns and aging: revising the evidences for humans and mice. Aging Dis 2013, 4:337-350

16. Dölle C, Flønes I, Nido GS, Miletic H, Osuagwu N, Kristoffersen S, Lilleng PK, Larsen JP, Tysnes O-B, Haugarvoll K, Bindoff LA, Tzoulis C: Defective mitochondrial DNA homeostasis in the substantia nigra in Parkinson disease. Nat Commun 2016, 7:13548

17. Kim J-H, Kim HK, Ko J-H, Bang H, Lee D-C: The relationship between leukocyte mitochondrial DNA copy number and telomere length in community-dwelling elderly women. PLoS One 2013, 8:e67227

18. Mengel-From J, Thinggaard $\mathrm{M}$, Dalgård $\mathrm{C}$, Kyvik KO, Christensen K, Christiansen L: Mitochondrial DNA copy number in peripheral blood cells declines with age and is associated with general health among elderly. Hum Genet 2014, 133:1149-1159

19. Wachsmuth M, Hübner A, Li M, Madea B, Stoneking M: Age-related and heteroplasmy-related variation in human mtDNA copy number. PLoS Genet 2016, 12:e1005939

20. O'Hara R, Tedone E, Ludlow A, Huang E, Arosio B, Mari D, Shay JW: Quantitative mitochondrial DNA copy number determination using droplet digital PCR with single cell resolution: a focus on aging and cancer. bioRxiv, 2019 [Epub] doi:10.1101/579789

21. Brosch M, Kattler K, Herrmann A, von Schönfels W, Nordström K, Seehofer D, Damm G, Becker T, Zeissig S, Nehring S, Reichel F, Moser V, Thangapandi RV, Stickel F, Baretton G, Röcken C, Muders M, Matz-Soja M, Krawczak M, Gasparoni G, Hartmann H, Dahl A, Schafmayer C, Walter J, Hampe J: Epigenomic map of human liver reveals principles of zonated morphogenic and metabolic control. Nat Commun 2018, 9:4150

22. Mita S, Schmidt B, Schon EA, DiMauro S, Bonilla E: Detection of "deleted" mitochondrial genomes in cytochrome-c oxidase-deficient muscle fibers of a patient with Kearns-Sayre syndrome. Proc Natl Acad Sci U S A 1989, 86:9509-9513

23. Oldfors A, Larsson NG, Holme E, Tulinius M, Kadenbach B, Droste M: Mitochondrial DNA deletions and cytochrome c oxidase deficiency in muscle fibres. J Neurol Sci 1992, 110:169-177

24. Müller-Höcker J, Seibel P, Schneiderbanger K, Kadenbach B: Different in situ hybridization patterns of mitochondrial DNA in cytochrome c oxidase-deficient extraocular muscle fibres in the elderly. Virchows Arch A Pathol Anat Histopathol 1993, 422:7-15

25. Larsson NG, Wang J, Wilhelmsson H, Oldfors A, Rustin P, Lewandoski M, Barsh GS, Clayton DA: Mitochondrial transcription factor $\mathrm{A}$ is necessary for mtDNA maintenance and embryogenesis in mice. Nat Genet 1998, 18:231-236

26. Rantanen A, Jansson M, Oldfors A, Larsson NG: Downregulation of Tfam and mtDNA copy number during mammalian spermatogenesis. Mamm Genome 2001, 12:787-792

27. Janes MS, Hanson BJ, Hill DM, Buller GM, Agnew JY, Sherwood SW, Cox WG, Yamagata K, Capaldi RA: Rapid analysis of mitochondrial DNA depletion by fluorescence in situ hybridization and immunocytochemistry: potential strategies for HIV therapeutic monitoring. J Histochem Cytochem 2004, 52:1011-1018

28. Yamagata K, Muro K, Usui J, Hagiwara M, Kai H, Arakawa Y, Shimizu Y, Tomida C, Hirayama K, Kobayashi M, Koyama A: Mitochondrial DNA mutations in focal segmental glomerulosclerosis lesions. J Am Soc Nephrol 2002, 13:1816-1823

29. Ashley N, Poulton J: Mitochondrial DNA is a direct target of anticancer anthracycline drugs. Biochem Biophys Res Commun 2009, 378:450-455 
30. Kukat C, Wurm CA, Spåhr H, Falkenberg M, Larsson N-G, Jakobs S: Super-resolution microscopy reveals that mammalian mitochondrial nucleoids have a uniform size and frequently contain a single copy of mtDNA. Proc Natl Acad Sci U S A 2011, 108:13534-13539

31. Chatre L, Ricchetti M: Large heterogeneity of mitochondrial DNA transcription and initiation of replication exposed by single-cell imaging. J Cell Sci 2013, 126:914-926

32. Chatre L, Ricchetti M: Prevalent coordination of mitochondrial DNA transcription and initiation of replication with the cell cycle. Nucleic Acids Res 2013, 41:3068-3078

33. Chatre L, Ricchetti M: mTRIP: an imaging tool to investigate mitochondrial DNA dynamics in physiology and disease at the single-cell resolution. Edited by Weissig V, Edeas M. In Mitochondrial Medicine: Volume I, Probing Mitochondrial Function. New York, NY: Springer New York, 2015. pp. 133-147

34. Baena-Del Valle JA, Zheng Q, Esopi DM, Rubenstein M, Hubbard GK, Moncaliano MC, Hruszkewycz A, Vaghasia A, Yegnasubramanian S, Wheelan SJ, Meeker AK, Heaphy CM, Graham MK, De Marzo AM: MYC drives overexpression of telomerase RNA (hTR/TERC) in prostate cancer. J Pathol 2018, 244:11-24

35. Holdhoff M, Guner G, Rodriguez FJ, Hicks JL, Zheng Q, Forman MS, Ye X, Grossman SA, Meeker AK, Heaphy CM, Eberhart CG, De Marzo AM, Arav-Boger R: Absence of cytomegalovirus in glioblastoma and other high-grade gliomas by real-time PCR, immunohistochemistry, and in situ hybridization. Clin Cancer Res 2017, 23:3150-3157

36. Brayton C, McKerlie C, Brown S: Analysis of phenotype. Edited by Pinkert CA. In Transgenic Animal Technology: A Laboratory Handbook. ed 3. New York, NY: Elsevier Inc., 2014. pp. 431-487

37. Wang XX, Luo Y, Wang D, Adorini L, Pruzanski M, Dobrinskikh E, Levi M: A dual agonist of farnesoid X receptor (FXR) and the G protein-coupled receptor TGR5, INT-767, reverses age-related kidney disease in mice. J Biol Chem 2017, 292:12018-12024

38. Wang F, Flanagan J, Su N, Wang L-C, Bui S, Nielson A, Wu X, Vo H-T, Ma X-J, Luo Y: RNAscope: a novel in situ RNA analysis platform for formalin-fixed, paraffin-embedded tissues. J Mol Diagn 2012, 14:22-29

39. Haffner MC, Esopi DM, Chaux A, Gürel M, Ghosh S, Vaghasia AM, Tsai H, Kim K, Castagna N, Lam H, Hicks J, Wyhs N, Biswal Shinohara D, Hurley PJ, Simons BW, Schaeffer EM, Lotan TL, Isaacs WB, Netto GJ, De Marzo AM, Nelson WG, An SS, Yegnasubramanian S: AIM1 is an actin-binding protein that suppresses cell migration and micrometastatic dissemination. Nat Commun 2017, 8:142

40. Marty L, Fort P: A delayed-early response nuclear gene encoding MRPL12, the mitochondrial homologue to the bacterial translational regulator L7/L12 protein. J Biol Chem 1996, 271:11468-11476

41. Wang Z, Cotney J, Shadel GS: Human mitochondrial ribosomal protein MRPL12 interacts directly with mitochondrial RNA polymerase to modulate mitochondrial gene expression. J Biol Chem 2007, 282:12610-12618

42. Borowski LS, Dziembowski A, Hejnowicz MS, Stepien PP, Szczesny RJ: Human mitochondrial RNA decay mediated by PNPase-hSuv3 complex takes place in distinct foci. Nucleic Acids Res 2013, 41:1223-1240

43. Mercer TR, Neph S, Dinger ME, Crawford J, Smith MA, Shearwood A-MJ, Haugen E, Bracken CP, Rackham O, Stamatoyannopoulos JA, Filipovska A, Mattick JS: The human mitochondrial transcriptome. Cell 2011, 146:645-658

44. Nelson I, Hanna MG, Wood NW, Harding AE: Depletion of mitochondrial DNA by ddC in untransformed human cell lines. Somat Cell Mol Genet 1997, 23:287-290

45. Schubert S, Heller S, Löffler B, Schäfer I, Seibel M, Villani G, Seibel P: Generation of Rho zero cells: visualization and quantification of the mtDNA depletion process. Int J Mol Sci 2015, 16:9850-9865

46. Brown TA, Clayton DA: Release of replication termination controls mitochondrial DNA copy number after depletion with 2',3'-dideoxycytidine. Nucleic Acids Res 2002, 30:2004-2010
47. Li B, Kaushik S, Kalinowski P, Kim B, Gershome C, Ching J, Poburko D: Droplet digital PCR shows the D-Loop to be an error prone locus for mitochondrial DNA copy number determination. Sci Rep 2018, 8:11392

48. Hirose M, Schilf P, Gupta Y, Zarse K, Künstner A, Fähnrich A, Busch H, Yin J, Wright MN, Ziegler A, Vallier M, Belheouane M, Baines JF, Tautz D, Johann K, Oelkrug R, Mittag J, Lehnert H, Othman A, Jöhren O, Schwaninger M, Prehn C, Adamski J, Shima K, Rupp J, Häsler R, Fuellen G, Köhling R, Ristow M, Ibrahim SM: Low-level mitochondrial heteroplasmy modulates DNA replication, glucose metabolism and lifespan in mice. Sci Rep 2018, 8:5872

49. Li F, Wang Y, Zeller KI, Potter JJ, Wonsey DR, O'Donnell KA, Kim J-W, Yustein JT, Lee LA, Dang CV: Myc stimulates nuclearly encoded mitochondrial genes and mitochondrial biogenesis. Mol Cell Biol 2005, 25:6225-6234

50. Liyanage SU, Hurren R, Voisin V, Bridon G, Wang X, Xu C, MacLean N, Siriwardena TP, Gronda M, Yehudai D, Sriskanthadevan S, Avizonis D, Shamas-Din A, Minden MD, Bader GD, Laposa R, Schimmer AD: Leveraging increased cytoplasmic nucleoside kinase activity to target mtDNA and oxidative phosphorylation in AML. Blood 2017, 129:2657-2666

51. Park E, Li N, Ye K, He M, Zhang Z, Sun H, Wang X, Anderson C, Luo Y, Gu Z, Ma X-J: Dissecting molecular pathways in human tumor vs. mouse stromal environment in patient-derived cancer models [abstract B03]. Clin Cancer Res 2016, 22 Suppl:B03

52. Wang H, Su N, Wang L-C, Wu X, Bui S, Nielsen A, Vo H-T, Luo Y, Ma X-J: Quantitative ultrasensitive bright-field RNA in situ hybridization with RNAscope. Methods Mol Biol 2014, 1211: 201-212

53. Antonicka H, Sasarman F, Nishimura T, Paupe V, Shoubridge EA: The mitochondrial RNA-binding protein GRSF1 localizes to RNA granules and is required for posttranscriptional mitochondrial gene expression. Cell Metab 2013, 17:386-398

54. Cinti S: Transdifferentiation properties of adipocytes in the adipose organ. Am J Physiol Endocrinol Metab 2009, 297:E977-E986

55. Farmer SR: Brown fat and skeletal muscle: unlikely cousins? Cell 2008, 134:726-727

56. Saely CH, Geiger K, Drexel H: Brown versus white adipose tissue: a mini-review. Gerontology 2012, 58:15-23

57. Yamazawa T, Nakamura N, Sato M, Sato C: Secretory glands and microvascular systems imaged in aqueous solution by atmospheric scanning electron microscopy (ASEM). Microsc Res Tech 2016, 79: $1179-1187$

58. Nyska A, Maronpot RR: Adrenal gland. Edited by Maronpot RR, Boorman GA, Gaul BW. In Pathology of the Mouse, Reference and Atlas. Vienna, IL: Cache River Press, 1999. pp. 509-536

59. Neuhaus JFG, Baris OR, Kittelmann A, Becker K, Rothschild MA, Wiesner RJ: Catecholamine metabolism induces mitochondrial DNA deletions and leads to severe adrenal degeneration during aging. Neuroendocrinology 2017, 104:72-84

60. Ertunc O, Zheng Q, Smearman E, Hicks J, Brosnan-Cashman J, Jones T, Trabzonlu L, Heaphy C, Meeker A, De Marzo A: A chromogenic in situ hybridization (CISH) technique for assessing telomeric DNA length in formalin-fixed tissue sections [abstract 1990]. Lab Invest 2019, 99:1-28

61. Font-Burgada J, Shalapour S, Ramaswamy S, Hsueh B, Rossell D, Umemura A, Taniguchi K, Nakagawa H, Valasek MA, Ye L, Kopp JL, Sander M, Carter H, Deisseroth K, Verma IM, Karin M: Hybrid periportal hepatocytes regenerate the injured liver without giving rise to cancer. Cell 2015, 162:766-779

62. Wang B, Zhao L, Fish M, Logan CY, Nusse R: Self-renewing diploid Axin2(+) cells fuel homeostatic renewal of the liver. Nature 2015, 524:180-185

63. Tang Y, Luo B, Deng Z, Wang B, Liu F, Li J, Shi W, Xie H, Hu X, Li J: Mitochondrial aerobic respiration is activated during hair follicle stem cell differentiation, and its dysfunction retards hair regeneration. PeerJ 2016, 4:e1821 
64. Koh CM, Bieberich CJ, Dang CV, Nelson WG, Yegnasubramanian S, De Marzo AM: MYC and prostate cancer. Genes Cancer 2010, 1:617-628

65. Trabzonlu L, Kulac I, Zheng Q, Hicks JL, Haffner MC, Nelson WG, Sfanos KS, Ertunc O, Lotan TL, Heaphy CM, Meeker AK, Yegnasubramanian S, De Marzo AM: Molecular pathology of highgrade prostatic intraepithelial neoplasia: challenges and opportunities. Cold Spring Harb Perspect Med 2019, 9:a030403

66. Rantanen A, Larsson NG: Regulation of mitochondrial DNA copy number during spermatogenesis. Hum Reprod 2000, 15 Suppl 2:86-91

67. Larsson NG, Oldfors A, Garman JD, Barsh GS, Clayton DA: Downregulation of mitochondrial transcription factor A during spermatogenesis in humans. Hum Mol Genet 1997, 6:185-191

68. Choudhury D, Levi M: Kidney aging-inevitable or preventable? Nat Rev Nephrol 2011, 7:706-717

69. O'Sullivan ED, Hughes J, Ferenbach DA: Renal aging: causes and consequences. J Am Soc Nephrol 2017, 28:407-420

70. Wang XX, Takahashi S, Libby AE, Myakala K, Jones BA, Bhasin K, Qi Y, Krausz K, Zerfas P, Panov J, Velenosi TJ, Patel DP, Daneshpajouhnejad P, Ginley B, Sarder P, Titievsky A, Sharov V, Ostretsov B, Kopp JB, Rosenberg AZ, Gonzalez FJ, Guha U, Brodsky L, Burris T, Levi M: ERR agonism reverses mitochondrial dysfunction and inflammation in the aging kidney. bioRxiv 2019 [Epub] doi: $10.1101 / 755801$

71. Derényi I, Szöllősi GJ: Hierarchical tissue organization as a general mechanism to limit the accumulation of somatic mutations. Nat Commun 2017, 8:14545

72. Bogenhagen D, Clayton DA: Mouse L cell mitochondrial DNA molecules are selected randomly for replication throughout the cell cycle. Cell 1977, 11:719-727
73. Magnusson J, Orth M, Lestienne P, Taanman J-W: Replication of mitochondrial DNA occurs throughout the mitochondria of cultured human cells. Exp Cell Res 2003, 289:133-142

74. Trinei M, Berniakovich I, Pelicci PG, Giorgio M: Mitochondrial DNA copy number is regulated by cellular proliferation: a role for Ras and p66(Shc). Biochim Biophys Acta 2006, 1757:624-630

75. Muncan V, Sansom OJ, Tertoolen L, Phesse TJ, Begthel H, Sancho E, Cole AM, Gregorieff A, de Alboran IM, Clevers H, Clarke AR: Rapid loss of intestinal crypts upon conditional deletion of the Wnt/Tcf-4 target gene c-Myc. Mol Cell Biol 2006, 26:8418-8426

76. Grayson AR, Walsh EM, Cameron MJ, Godec J, Ashworth T, Ambrose JM, Aserlind AB, Wang H, Evan G, Kluk MJ, Bradner JE, Aster JC, French CA: MYC, a downstream target of BRD-NUT, is necessary and sufficient for the blockade of differentiation in NUT midline carcinoma. Oncogene 2014, 33:1736-1742

77. Berger E, Rath E, Yuan D, Waldschmitt N, Khaloian S, Allgäuer M, Staszewski O, Lobner EM, Schöttl T, Giesbertz P, Coleman OI, Prinz M, Weber A, Gerhard M, Klingenspor M, Janssen K-P, Heikenwalder M, Haller D: Mitochondrial function controls intestinal epithelial stemness and proliferation. Nat Commun 2016, 7:13171

78. Reznik E, Miller ML, Şenbabaoğlu Y, Riaz N, Sarungbam J, Tickoo SK, Al-Ahmadie HA, Lee W, Seshan VE, Hakimi AA, Sander C: Mitochondrial DNA copy number variation across human cancers. Elife 2016, 5:e10769

79. Müller-Höcker J, Horvath R, Schäfer S, Hessel H, Müller-Felber W, Kühr J, Copeland WC, Seibel P: Mitochondrial DNA depletion and fatal infantile hepatic failure due to mutations in the mitochondrial polymerase $\gamma$ (POLG) gene: a combined morphological/enzyme histochemical and immunocytochemical/biochemical and molecular genetic study. J Cell Mol Med 2011, 15:445-456 